\title{
Enhancing the Mechanical Properties of Cross-Linked Rubber-Toughened Nanocomposites via Electron Beam Irradiation
}

\author{
N. A. Jamal, ${ }^{1}$ H. Anuar, ${ }^{1}$ and A. R. Shamsul Bahri ${ }^{2}$ \\ ${ }^{1}$ Department of Manufacturing and Materials Engineering, Faculty of Engineering, International Islamic University Malaysia, P.O. \\ Box 10, Kuala Lumpur 50728, Malaysia \\ ${ }^{2}$ Crop Improvement and Protection Unit, Production Development Division, Rubber Research Institute Malaysia (RRIM), Sungai \\ Buloh, Selangor Darul Ehsan 47000, Malaysia \\ Correspondence should be addressed to N. A. Jamal, ayuni_jamal@yahoo.com
}

Received 7 November 2010; Revised 13 March 2011; Accepted 14 March 2011

Academic Editor: Guifu Zou

Copyright () 2011 N. A. Jamal et al. This is an open access article distributed under the Creative Commons Attribution License, which permits unrestricted use, distribution, and reproduction in any medium, provided the original work is properly cited.

Improving the mechanical properties of a pristine system is the main target of developing nanocomposites. The nanocomposites systems were first prepared via intercalation technique with different organophilic montmorillonite (OMMT) loading. Two types of cross-linking techniques were applied, namely, as maleic anhydride polyethylene (MAPE) and electron beam (EB) irradiated system. The effectiveness of these systems was then compared with the control one and analyzed based on the mechanical tests and morphological examination. The mechanical tests revealed that control, MAPE, and EB irradiated systems had attained the optimum mechanical properties at 4 vol\% OMMT content. EB irradiated unit of a dose of $100 \mathrm{kGy}$ showed excellent mechanical properties with higher crosslinking degree which were proved by gel content analysis. X-ray diffraction (XRD) analysis confirmed the existence of delamination structure with MAPE and EB irradiation techniques based on the disappearance of characteristic peak. The degree of delamination was further investigated by transmission electron microscope (TEM).

\section{Introduction}

Compatibilizer or cross-linking agent is commonly introduced in a nanocomposite purposely to reduce the surface tension between immiscible polymers and filler as well as to improve the surface adhesion of filler. This is done to obtain the optimum filler dispersion which will improve properties of nanocomposite. The compatibilizer is a functionalized nanocomposite which prevents segregation of the polymer components in the polymer. Moreover, cross-linking agent is proved to enhance the rigidity of the polymer $[1,2]$. Compatibilizing agents are typically a molecule having one hydrophilic and one organophilic functional group. Compatibilizers containing maleic anhydride functionalities are commonly used and are effective in improving physical properties of composites. A few studies claimed that the miscibility of polymer matrix with clay can be enhanced by introducing compatibilizers containing polar groups, such as maleated polyethylene (MAPE), carboxylated PE, and so on $[3,4]$. In this study, maleated polyethylene, MAPE, has been applied as a compatibilizer agent for the nanocomposite system.

Irradiation processing has been used for many years to modify the properties of formed polymer parts. The property enhancements achieved include increased operating temperature, improved mechanical properties, and increased chemical and solvent resistance. It should be noted that polymer structure influences the cross-linking ability of polymer. Chain cross-linking and scission are the two reactions that occur during EB processing of polymers. Polymers typically undergo simultaneous scission and crosslinking, but, in most cases, with one or the other clearly predominating $[5,6]$. Cross-linking is the intermolecular bond formation of polymer chain. The degree of crosslinking is proportional to the radiation dose [7]. Much works have been done on radiation cross-linking of uncross-linked 
polymers and cross-linking of various rubbers and plastics by electron beam irradiation [7-9].

In contrast, scission is the opposite process of crosslinking in which the rupturing of $\mathrm{C}-\mathrm{C}$ bond occurs. Scission reduces cross-linking efficiency and degrades the properties of polymers (chemical resistance, mechanical, and thermal properties). The current study aims to vary and highlight the interest of EB irradiation technique for HDPE/EPDM, where pristine composites and nanocomposites were prepared with different irradiation doses rate and different OMMT loadings. The results obtained for the EB irradiated system were then compared with control and MAPE systems for the determination of the optimum system.

\section{Experimental Design}

2.1. Materials. Homopolymer high-density polyethylene (HDPE); (melt index: 3-6 g/10 min, density: $900 \mathrm{~kg} / \mathrm{cm}^{3}$ ) supplied by Cementhai Chemicals Group, Thailand and ethylene propylene diene monomer (EPDM) supplied by Centre West Sdn Bhd, Malaysia were used as the base polymer matrix. MAPE-Polybond ${ }^{@}$ 3009, obtained from Uniroyal Chemical Company, was used as a coupling agent to improve surface adhesion. Commercially available organophilic montmorillonite (OMMT) surface modified with $15-35 \mathrm{wt} \%$ octadecylamine and $0.5 \mathrm{wt} \%$ aminopropyltriethoxysilane obtained from Sigma-Aldrich Group, Malaysia was used as reinforcing agent to prepare nanocomposites.

2.2. Compounding. Melt blending of HDPE (70 vol\%) and EPDM rubber (30 vol\%) as polymer matrix was carried out first in an internal mixer (Thermo Haake Rheomix 600P). Then, HDPE/EPDM blend was mixed with MAPE and OMMT. The content of MAPE agent was fixed at 3 vol\% whereas the contents of OMMT were varied between $2,4,6$, and $8 \mathrm{vol} \%$. The melt mixing conditions were $150^{\circ} \mathrm{C}$ and at a rotor speed of $100 \mathrm{rpm}$. Prior to mixing, the polymer matrix and the nano clays were dehumidified in a dry oven at $110^{\circ} \mathrm{C}$ for a period of $1 \mathrm{hr}$. Details on the preparation of HDPE/EPDM and HDPE/EPDM filled OMMT are summarized in Tables 1 and 2.

2.3. Specimen Preparation. Subsequently, the blended samples were compression molded as per ASTM-F-412 using a compression molding machine at a temperature range of $135-155^{\circ} \mathrm{C}, 8$ tone metric pressures for $14 \mathrm{~min}$.

2.4. High-Energy EB Irradiation. The melt compounding samples were exposed under high-energy EB irradiation at different unit of dose of 50,100, 150, and $200 \mathrm{kGy}$ at room temperature using a $3 \mathrm{MeV}$ electron beam accelerator. The acceleration energy, beam current, and dose rate were set to $2 \mathrm{MeV}, 2 \mathrm{~mA}$, and $50 \mathrm{kGy} /$ pass, respectively.

\section{Characterization Techniques}

3.1. Mechanical Properties. Test specimens for analyzing mechanical properties were initially conditioned at $23 \pm$ $1^{\circ} \mathrm{C}$ and $55 \pm 2 \% \mathrm{RH}$ for $24 \mathrm{hr}$ prior to testing. These conditioned specimens were subjected to mechanical testing, and an average from the five testing measurements was reported. The corresponding standard deviation along with the measurement uncertainty value for the experimental data showing maximum deviation was also included.

3.2. Tensile Test. Specimens with dimensions of $125 \times 1 \times$ $1 \mathrm{~mm}^{3}$ were subjected to a tensile test as per ASTM F412, using Instron 5567 machine with $5 \mathrm{kN}$ load. Crosshead speed and gauge lengths were set to $50 \mathrm{~mm} / \mathrm{min}$ and $60 \mathrm{~mm}$.

3.3. Flexural Test. Specimens with $125 \times 15 \times 3 \mathrm{~mm}$ dimension were tested in accordance with ASTM D790 by using Instron 5567 machine. A span of $100 \mathrm{~mm}$ was used in a $5 \mathrm{kN}$ load cell with crosshead speed of $50 \mathrm{~mm} / \mathrm{min}$.

3.4. Impact Test. Notched Izod impact test as specified by ASTM D256 standard test method was applied by using Ceast 6545/000 model. Specimens with $62 \times 15 \times 3 \mathrm{~mm}^{3}$ dimension were subjected to an impact test with $2.54 \mathrm{~mm}$ depth of notch. Before the testing takes place, each sample is immersed into liquid nitrogen for about 30 seconds. The energy absorbed by the specimen in the breaking process is known as the breaking energy $(\mathrm{J} / \mathrm{m})$.

3.5. Gel Content Analysis. The gel content of the samples was determined by boiling the samples with xylene for 24 hours in accordance with ASTM D2765 procedure. The extracted samples were vacuum dried to constant weight for 16 hours at $75^{\circ} \mathrm{C}$. The gel content was calculated as the ratio of weight of dried sample after extraction to the initial weight of the sample before extraction. The results reported were the average of three specimens. The gel content percentage of cross-linked samples was calculated using the formula below:

$$
(\%) \text { Gel content }=\frac{\text { weight after extraction }}{\text { weight before extraction }} \times 100 \text {. }
$$

3.6. X-Ray Diffraction Analysis (XRD). X-ray diffractograms of OMMT and the nanocomposites were recorded using Shimadzu 6000 (Japan), X-ray crystallographic unit equipped with nickel filtered $\mathrm{Cu} \mathrm{K} \alpha$ radiation source operated at $40 \mathrm{kV}$ and $40 \mathrm{~mA}$. The basal spacing or $\mathrm{d}_{001}$ reflection of the samples was calculated from Bragg's equation by monitoring the diffraction angle $2 \theta$ from 2 to $10^{\circ}$.

\subsection{Morphological Examination}

3.8. Transmission Electron Microscope (TEM). The morphology of the nanocomposites was observed using a JEOL JEM electron microscope with an accelerating voltage of $100 \mathrm{kV}$. Ultrathin specimens of $100 \mathrm{~nm}$ thickness were cut from the middle section of the compression molded bar using a Leica 
TABLE 1: Preparation of HDPE/EPDM blend (polymer matrix) via melt blending method.

\begin{tabular}{lccc}
\hline Polymers & Polymers content (vol\%) & Ratio of HDPE to EPDM blend & Total composition \\
\hline High density polyethylene (HDPE) & 70 & $70: 30$ & 100 \\
Ethylene propylene diene monomer (EPDM) & 30 & $70: 30$ & 100 \\
\hline
\end{tabular}

TABle 2: Composition, parameters, and modification of nanocomposites prepared.

\begin{tabular}{|c|c|c|c|c|c|}
\hline Systems & Polymer matrix & $\begin{array}{l}\text { Polymer matrix } \\
\text { content (vol\%) }\end{array}$ & $\begin{array}{l}\text { OMMT content } \\
(\text { vol } \%)\end{array}$ & $\begin{array}{c}\text { Surface } \\
\text { modification }\end{array}$ & $\begin{array}{c}\text { Total } \\
\text { composition }\end{array}$ \\
\hline Control & HDPE/EPDM & 100 & - & - & 100 \\
\hline MAPE & HDPE/EPDM & 97 & - & 3 vol\% MAPE & 100 \\
\hline Control-50 kGy & HDPE/EPDM & 100 & - & $\begin{array}{c}\text { Electron beam } \\
\text { irradiation at } \\
50 \mathrm{kGy}\end{array}$ & 100 \\
\hline Control-100 kGy & HDPE/EPDM & 100 & 一 & $\begin{array}{c}\text { Electron beam } \\
\text { irradiation at } \\
50 \mathrm{kGy}\end{array}$ & 100 \\
\hline Control-150 kGY & HDPE/EPDM & 100 & - & $\begin{array}{c}\text { Electron beam } \\
\text { irradiation at } \\
50 \mathrm{kGy}\end{array}$ & 100 \\
\hline Control-200 kGy & HDPE/EPDM & 100 & - & $\begin{array}{c}\text { Electron beam } \\
\text { irradiation at } \\
50 \mathrm{kGy}\end{array}$ & 100 \\
\hline Control/OMMT & HDPE/EPDM & $98,96,94,92$ & $2,4,6$, and 8 & - & 100 \\
\hline MAPE/OMMT & HDPE/EPDM & $95,93,91,88$ & $2,4,6$, and 8 & 3 vol $\%$ MAPE & 100 \\
\hline 50 kGy/OMMT & HDPE/EPDM & $98,96,94,92$ & $2,4,6$, and 8 & $\begin{array}{c}\text { Electron beam } \\
\text { irradiation at } \\
50 \mathrm{kGy}\end{array}$ & 100 \\
\hline 100 kGy/OMMT & HDPE/EPDM & $98,96,94,92$ & $2,4,6$, and 8 & $\begin{array}{c}\text { Electron beam } \\
\text { irradiation at } \\
50 \mathrm{kGy}\end{array}$ & 100 \\
\hline 150 kGy/OMMT & HDPE/EPDM & $98,96,94,92$ & $2,4,6$, and 8 & $\begin{array}{c}\text { Electron beam } \\
\text { irradiation at } \\
50 \mathrm{kGy}\end{array}$ & 100 \\
\hline 200 kGy/OMMT & HDPE/EPDM & $98,96,94,92$ & $2,4,6$, and 8 & $\begin{array}{c}\text { Electron beam } \\
\text { irradiation at } \\
50 \mathrm{kGy}\end{array}$ & 100 \\
\hline
\end{tabular}

Control system = untreated or nonirradiated system; OMMT = organophilic montmorillonite; HDPE = high-density polyethylene; EPDM = ethylene propylene diene monomer; MAPE $=$ maleic anhydride polyethylene .

ultra microtome. The specimens were collected on a trough filled with water and placed on a 200 -mesh grid.

\section{Results and Discussion}

4.1. Tensile Strength and Modulus. The effect of different clay loading on control, MAPE, and EB irradiated systems is demonstrated in Figures 1 and 2. It is observed that the tensile strength and modulus for all the nanocomposite system began to increase up to $4 \mathrm{vol} \%$ of OMMT. As clay loading exceeded $4 \mathrm{vol} \%$, the tensile strength and modulus of all the system were found to decrease. Similar improvement in tensile strength and modulus were also reported by previous researchers in their work on any polymer/organoclay nanocomposites $[10,11]$. The primary cause for such improvement was attributed to the presence of immobilized or partially mobilized polymer phases. This is due to the better interaction of polymer chains with clays and large number of interacting molecules due to the dispersed phase volume ratio characteristic of largely intercalated and exfoliated clay platelets as evidenced by TEM micrograph.

Tensile strength and modulus of both pristine composite and nanocomposite were further improved with MAPE agent, as evidenced in Figures 1 and 2. An increase of 33.79\% and $21.52 \%$ in tensile strength and modulus were observed for MAPE system as compared to the control one where only $30.66 \%$ and $19.52 \%$ increment with 4 vol\% OMMT were elucidated. This slight increase was believed due to accomplish a larger interlayer distance as the molecular structure of MAPE contains anhydride group highly attracted to OMMT sheets and a longer nonpolar fragment attracted to the HDPE/EPDM matrix.

An increment of $47.14 \%, 40.24 \%, 39.84 \%$, and $35.74 \%$ in tensile strength were observed for EB irradiated system 
TABLE 3: Interplanar spacing and diffraction angle values for control, MAPE, and EB irradiated systems.

\begin{tabular}{llc}
\hline Systems & $2 \theta\left(^{\circ}\right)$ & Interplanar spacing, $d(\AA)$ \\
\hline Control/4 vol\% OMMT & 3.570 & 24.73 \\
MAPE/4 vol\% OMMT & 3.218 & 28.72 \\
EB irradiated-100 kGy/4 vol\% OMMT & 2.845 & 31.03 \\
\hline
\end{tabular}

with doses rate of $100,50,150$, and $200 \mathrm{kGy}$. On the other hand, $49.54 \%, 31.43 \%, 23.56 \%$, and $22.33 \%$ improvement in modulus were observed at unit of doses of 100, 50, 150, and $200 \mathrm{kGy}$. The tensile strength and modulus maximized at $18.51 \mathrm{MPa}$ and $701.39 \mathrm{MPa}$ at $4 \mathrm{vol} \%$ of OMMT and $\mathrm{EB}$ irradiation unit of a dose of $100 \mathrm{kGy}$. This indicates the formation of radiation induced cross-linking in the rubber and plastic phases as confirmed by the gel content analysis. At higher doses rate, the tensile strength decreased due to the breakdown of the network structure. Evidently, as revealed by XRD and TEM examinations, clay aggregates were broken up and acceptable uniform dispersion of clay particles can be achieved with the aid of EB irradiation.

4.2. Elongation at Break. A moderate increment of the elongation at break with initial incorporation of $2 \mathrm{vol} \%$ organoclay loading and followed by a sudden dropping of elongation at break upon $6 \mathrm{vol} \%$ loading of organoclay is obtained as in Figure 3. Similar results were reported before $[12,13]$. The improvement in elasticity may be attributed to the plasticizing effect of the OMMT gallery and to their contribution to the formation of dangling chains but also probably to conformational effects at the clay and matrix interface $[14,15]$.

Further $9.8 \%$ reduction in elongation at break at optimum clay loading of $4 \mathrm{vol} \%$ was observed for MAPE system. This is believed to be due to the MAPE reduced chain slippage on the surface of the fillers by the reaction both of filler and matrix. As a result, the elongation at break of the MAPE nanocomposite decreased.

EB irradiated system experienced a continuous decrease in elongation at break with increased unit of dose. Reductions of $10.44 \%, 11.23 \%, 15.68 \%$, and $21.19 \%$ at optimum clay loading of $4 \mathrm{vol} \%$ are obtained with unit of dose of 100 , 50,150 , and $200 \mathrm{kGy}$. Generally, increasing radiation dose resulted in reduction of elongation at break of nanocomposite. Therefore, the reduction in elongation at break at higher filler loading could be attributed to the reduced segmental mobility of polymer chains, which resulted from chain degradation. Also, increasing irradiation dose led to increased cross-linked density and hence hindered the extension of chains which resulted in lower value of elongation at break. The enhanced cross-linking density may not necessarily increase the tensile properties of the polymer matrix as in the case of elongation break due to the EB irradiation-induced scission of polymer chain as well as brittleness character.

4.3. Flexural Strength and Modulus. The effect of organoclay loading on the flexural strength and modulus for control, MAPE, and EB irradiated systems is illustrated in Figures 4 and 5. The same trend in flexural strength and modulus were obtained as in tensile properties. A moderate increase in flexural strength and modulus was observed for MAPE system. This indicates that this functionalization lowered the hydrophobicity of polymer matrix, imparting polarity which makes it more compatible with hydrophilic clay.

A significant increase in flexural strength and modulus were observed with EB irradiated system. An improvement of $39.27 \%$ and $39.94 \%$ was achieved at $100 \mathrm{kGy}$ unit of dose. As expected, the flexural strength and modulus increased with radiation dose and continued to decrease at doses rate of $150 \mathrm{kGy}$ and above. Such an increase may be attributed to the transfer of electron energy to the polymer. According to Park et al., [15], during irradiation, the electron loses kinetic energy and momentum due to interactions with the polymer. This process will lead to bond cross-linking rather than scission depending on the structure of the polymer particularly breakage of chemical bonding. In contrast, the decrease in strength and modulus at higher doses rate has been attributed to the fact that already formed cross-linked network had become smaller. This is due to the continuing of cross-linking process between the nanocomposites molecules.

4.4. Impact Strength. The effect of clay loading on control, MAPE, and EB irradiated system of notched Izod impact strength is depicted in Figure 6. It can be seen that a moderate increment on the impact strength for all pristine and nanocomposite system with initial incorporation of 2 vol\% OMMT followed by a sudden dropping at $6 \mathrm{vol} \%$ of OMMT loading. This is possible due to the presence of acceptable amount of rubber compound as impact modifier along with OMMT due to the dispersion of rubber phase as spherical domains in polymer matrix, and, it contributes to improve the toughness. Similar pattern behavior was also reported in previous studies [16-18].

The presence of MAPE significantly modified the impact strength value by $19.43 \%$ as compared to control system at the optimum level of 4 vol\% OMMT loading. This is believed to be due to the higher diffusion of the lower molecular weight MAPE chains through the polymer matrix and its easier penetration into the octadecylamine group formed at the OMMT surface.

EB irradiated system had obtained the highest value of impact strength as compared to control and MAPE systems. The impact strength of EB irradiated increased with clay loading but decreased as clay loading reached 6 vol\% and above. For unfilled composites, an increase 


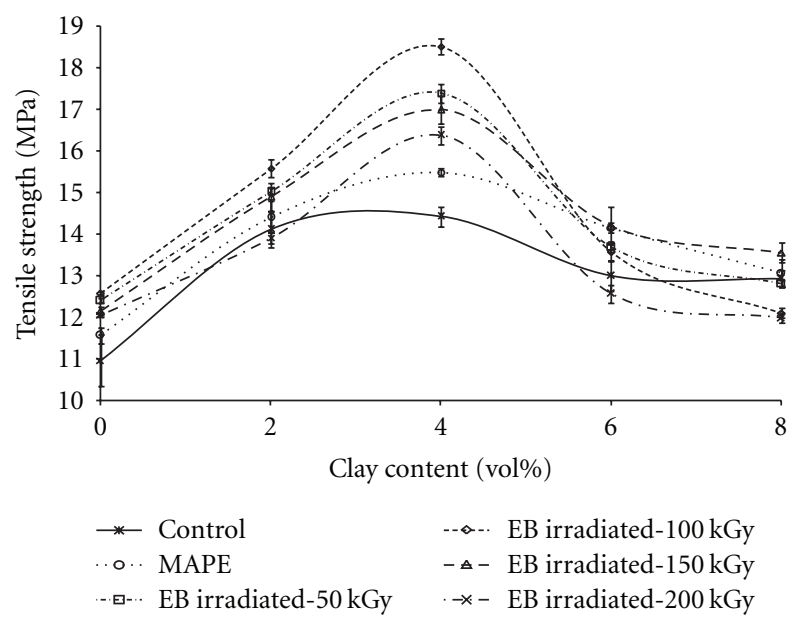

FIGURE 1: Effect of OMMT content and surface modification on tensile strength for control, MAPE, and EB irradiated systems.

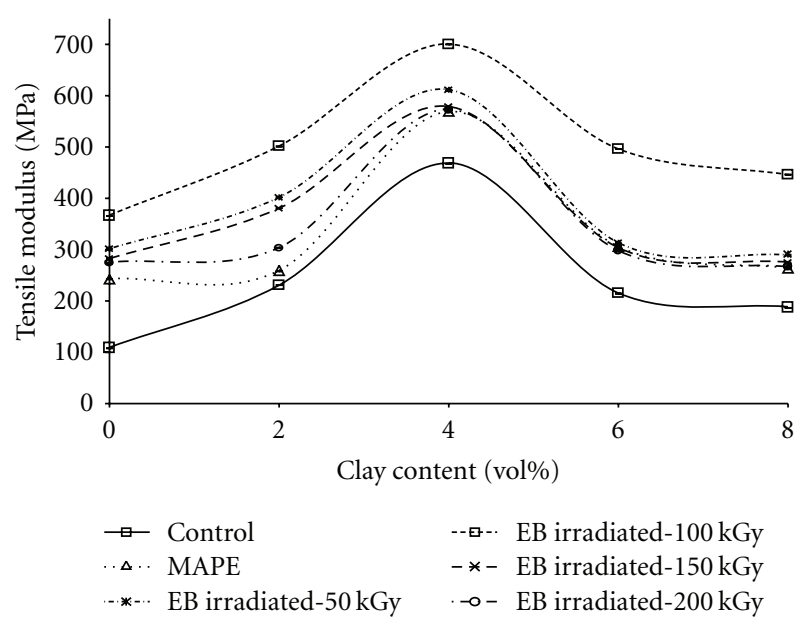

Figure 2: Effect of OMMT content and surface modification on tensile modulus for control, MAPE, and EB irradiated systems.

of $29.51 \%$ is achieved at optimum $100 \mathrm{kGy}$ unit of dose followed by $22.96 \%, 21.63 \%$, and $20.01 \%$ improvement at 50,150, and $200 \mathrm{kGy}$. Moreover, the introduction of 4 vol\% OMMT loading enhanced the impact strength by $25.34 \%, 20.22 \%, 17.54 \%$, and $14.61 \%$ at $100,50,150$, and $200 \mathrm{kGy}$. This is might be due to the cross-linking effect in pristine composite and nanocomposite systems which resulted in three-dimensional and gel-like structures. In contrast, the reduction in impact strength has contributed to the radiation-induced scission which caused the break age of carbon-carbon bond.

4.5. Gel Content Analysis. The susceptibility of control composites as well as nanocomposites to cross-linking process was estimated from the gel fraction determination. The gel content of control, MAPE-treated, and irradiated samples increased with the presence of OMMT at optimum loading of 4 vol\%. As shown in Figure 7, there was no gel

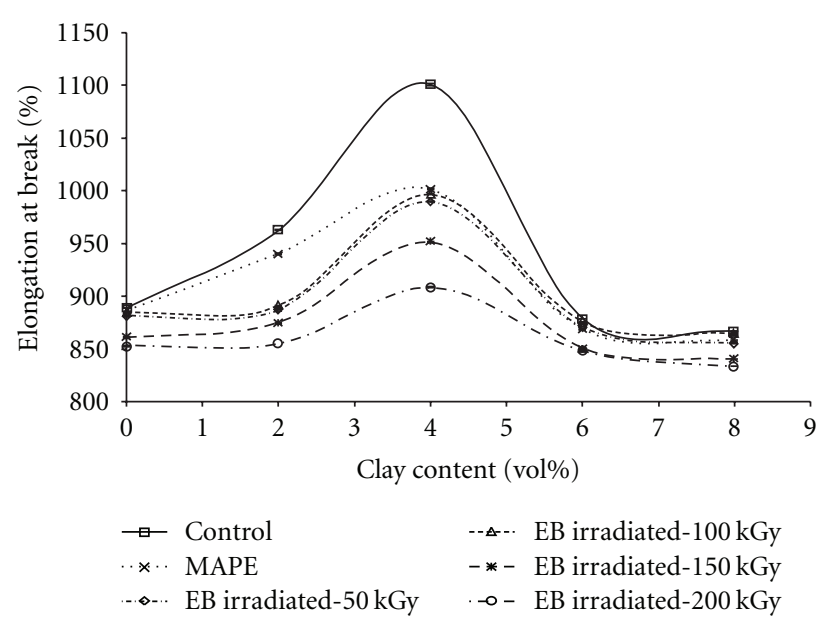

Figure 3: Effect of OMMT content and surface modification on elongation at break for control, MAPE, and EB irradiated systems.

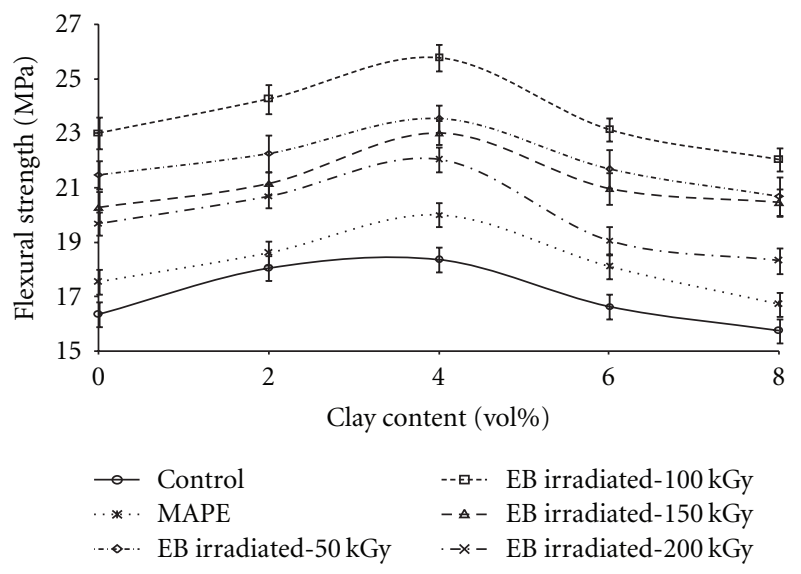

Figure 4: Effect of OMMT content and surface modification on flexural strength for control, MAPE, and EB irradiated systems.

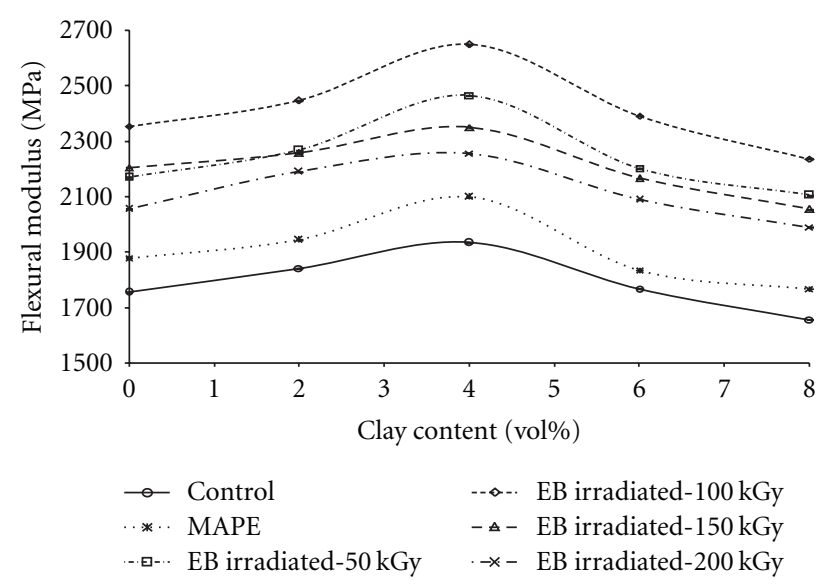

FIGURE 5: Effect of OMMT content and surface modification on flexural modulus for control, MAPE, and EB irradiated systems. 


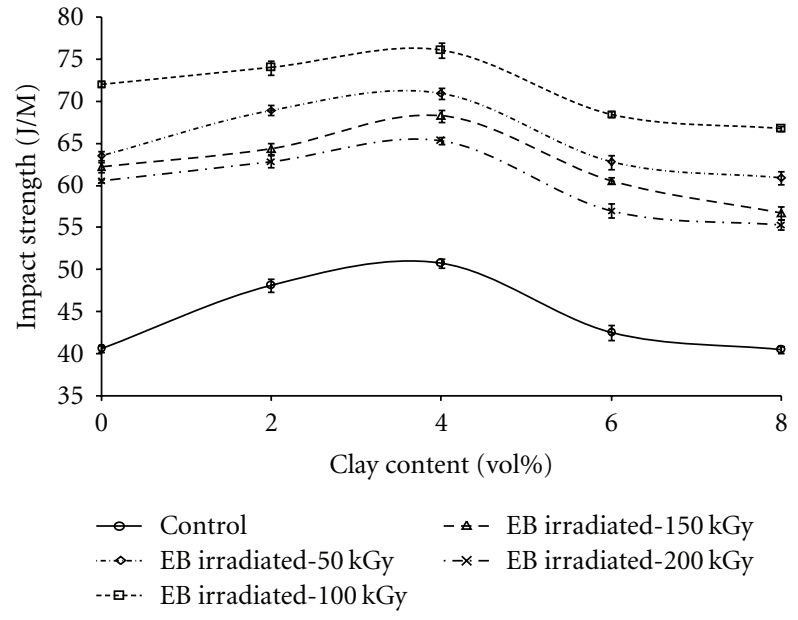

FIGURE 6: Effect of OMMT content and surface modification on impact strength for control, MAPE, and EB irradiated systems.

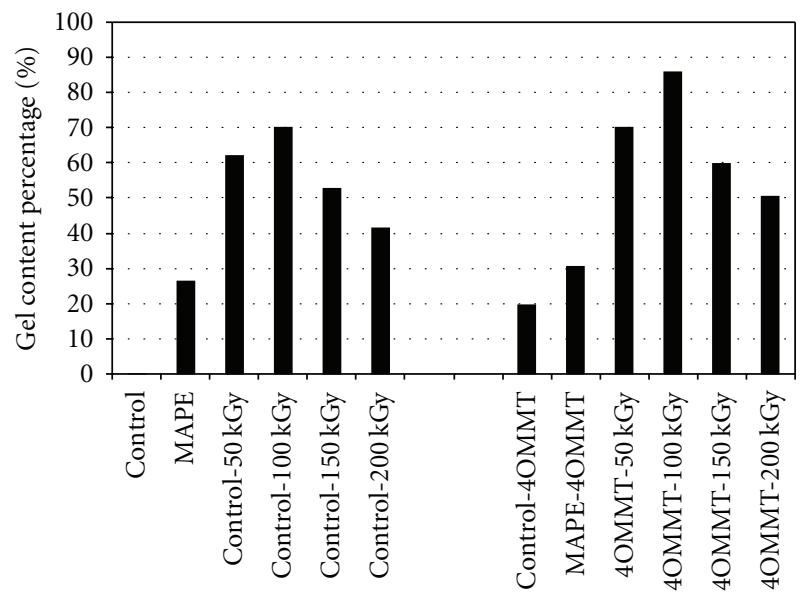

FIGURE 7: Effect of OMMT content and surface modification on gel content.

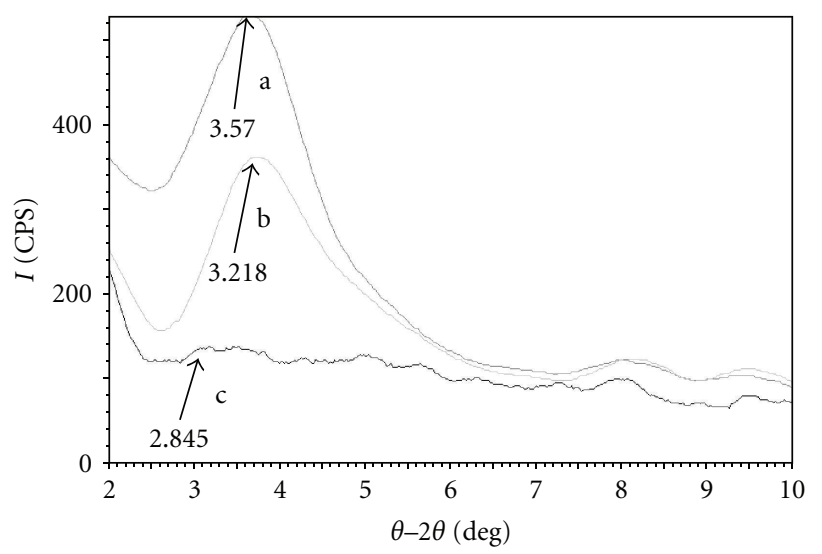

(a) Control/4 vol\% OMMT

(b) MAPE $/ 4$ vol $\%$ OMMT

(c) EB irradiated-100 kGy/4 vol\% OMMT

FIGURE 8: XRD analysis for control, MAPE, and EB irradiated systems.

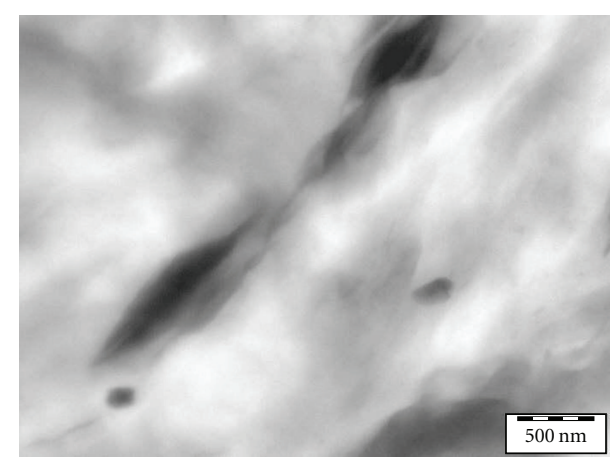

FIGURE 9: TEM micrograph of control system (untreated).

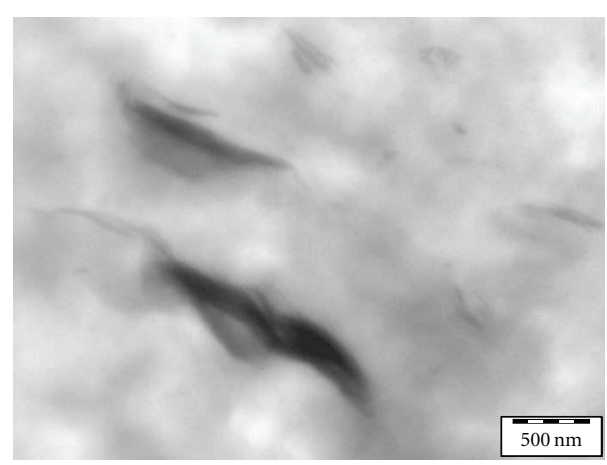

FIGURE 10: TEM micrograph of MAPE system.

formation observed for control system without the addition of OMMT. Only $20 \%$ of gel formation was obtained at $4 \mathrm{vol} \%$ OMMT loading. The gel percentage of pristine composite increased with OMMT loading for both untreated and treated nanocomposites. This may be attributed to a better dispersion (either partial or fully exfoliated of nano particles) in the nanocomposites. The better dispersion of nano clay resulted in a more uniform distribution of water molecules in the polymer matrix, which leads to higher gel content.

In this study, the tensile strength property was identified to affect the extent of cross-linking via gel formation. A linear relationship is obtained between the tensile strength and gel formation percentage where higher tensile strength will result in higher gel percentage. An improvement of $26.77 \%$ and $30.85 \%$, is achieved for both unfilled composite and nanocomposites with MAPE. This shows that MAPE agent can act as plasticizer and decrease the interfacial energy between the two phases. Thus, the wetting of the OMMT with polymer matrix material has been improved. As a result, the percentage of gel content increased.

For EB irradiated system, the gel content increased rapidly by increasing the radiation unit of dose up to $100 \mathrm{kGy}$, beyond which it slowly decreased. An enhancement of $62.49 \%, 70.38 \%, 53.17 \%$, and $41.81 \%$ was observed for pristine composite. Moreover, for nanocomposites system, an improvement of $70.44 \%, 86.02 \%, 60.25 \%$, and $50.71 \%$ was obtained in gel formation. As EPDM and HDPE are organic polymers which are categorized radiation crosslinkable materials then such formation of cross-links upon 


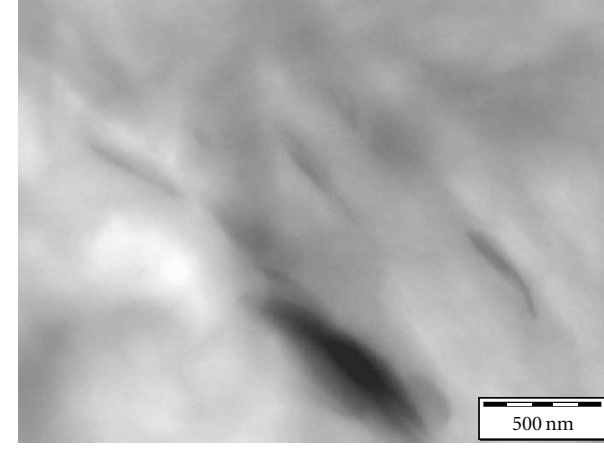

FIGURE 11: TEM micrograph of EB irradiated system.

irradiation are to be expected in them. Kim and Nho [18] mentioned that the degree of cross-linking increases with irradiation dose rate due to the increase in the concentration of the free radicals. As the cross-linking and the chain scission during irradiation occur simultaneously, the decrease in gel formation beyond unit of dose of $100 \mathrm{kGy}$ might be attributed to the loosening of the network upon irradiation.

4.6. X-Ray Diffraction Analysis (XRD). Judging from the above results, the optimum OMMT content and EB irradiation unit of dose were taken as $4 \mathrm{vol} \%$ and $100 \mathrm{kGy}$. Therefore, from Section 4.6 until 4.7, the discussions were based on these optimum parameters. The changes in the interlayer distance of clay can generally be elucidated using XRD. The peak for control system (untreated or unirradiated) visibly appeared with highest intensity, indicating that most of the clay is still in the original stacking condition. This is evidenced by the highest diffraction peak which was about $24.73 \AA$. As discussed by Olalekan et al., 2010 [19], such a characteristic implies that nano particles were not well dispersed in the composite and thus lead to the formation of agglomerates (characteristics of nanomaterials) in the system. The diffraction angle and interplanar spacing values are summarized in Table 3.

As MAPE was added, the (001) peak still appeared, but its intensity was obviously lowered. This suggests that the diffraction peak of MAPE system has shifted toward lower angle and higher diffraction peak which were about $0.36^{\circ}$ and $3.9 \AA$. This shows that the polymer matrix is ready to enter the galleries of OMMT layers resulting in broadening of XRD peak. As a result, the interlayer spacing of the clay increased, and the interaction of the layers should be weakened. However, in the current study, some clay still kept the original stacking condition with MAPE as revealed by TEM micrograph.

On the other hand, nanocomposites with exposure to EB irradiation revealed intercalated structure based on the absence of any basal reflections in the XRD patterns as evidenced by TEM image. It can be seen from Figure 8 and Table 3 that the diffraction peak was significantly shifted towards lower angle and higher diffraction peak which were about $0.83^{\circ}$ and $6.30 \AA$. This suggested that the face-toface interaction between the OMMT particles layers was decreased at the benefit of improving the surface interaction between OMMT particles and polymer matrix. Moreover, this might also imply that the interlayer distance between the OMMT particles have become shrinked due to the formation of cross-linking structure [20]. However, the shift in the diffraction peak to lower $2 \theta$ value may not necessarily offer evidence for complete exfoliation, it may also indicate the intercalated structure, which has been confirmed by TEM examination.

4.7. Transmission Electron Microscope (TEM). The nanometer scale dispersion of the treated clays OMMT within the polymer matrix is further corroborated with TEM images as depicted in Figures 9, 10, and 11, respectively. The lighter region represents HDPE part and the dark region represents EPDM part whereas the dark lines corresponding to silicate layers (OMMT).

Silicate layers with bulky stacks were found to be intercalated in the polymer matrix for control and MAPE systems as evidenced in Figures 9 and 10, respectively. In the case of control system, the nonuniform of OMMT agglomerates was easily detected. Moreover, it can be seen that the dispersion of the clay particles was poor with large aggregates observed.

However, in the case of EB irradiated system as shown in Figure 11, the large aggregates of clay layers had broken down between three and four aggregates corresponding to the intercalation structure which resulted in being slightly smoother and finer as compared to control and MAPE systems. This indicates that the surface interaction between OMMT particles and HDPE/EPDM matrix had slightly improved. On the other hand, modification of clay with high-energy EB irradiation lowered the electrostatic interactions between the clay layers and enlarged their intragallery spacing thus facilitating intercalation and exfoliation with efficient dispersion of the clay [20-22]. It also demonstrated superior nanocomposites performance as discussed in the Mechanical Properties section.

4.8. Conclusion. The effects of MAPE and EB irradiation as cross-linking agents on the mechanical properties and gel content formation of nanocomposites were investigated in the current study. The findings are then summarized as follows.

(1) A good balance of properties in terms of stiffness and strength was achieved at $4 \mathrm{vol} \%$ OMMT content.

(2) Surface modification through electron beam (EB) radiation has induced high cross-linking as evidenced by gel content analysis, thus enhancing the mechanical properties of unfilled and filled nanocomposites systems.

(3) A linear relationship between mechanical properties and gel content has been achieved, where the higher the mechanical properties, the greater the gel formation. 
(4) High-energy EB irradiation can be an alternative as better impact and surface modification of nanocomposites system in which it can replace the role of chemical cross-linking which has been applied in many studies for decades.

\section{Acknowledgments}

The authors wish to express their gratitude to University Malaysia Perlis, Ministry of Higher Education (MOHE), and International Islamic Malaysia University for the financial assistance and all the staff in MRB, MINT, SIRIM, and IIUM for their help.

\section{References}

[1] L. Song, M. Li, Y. Hu, and H. Lu, "Study on preparation and properties of silane-crosslinked polyethylene/ magnesium hydroxide/ montmorillonite nanocomposites," Journal of Fire Sciences, vol. 26, no. 6, p. 498, 2008.

[2] M. N. Satheesh Kumar and Siddaramaiah, "Studies on melamine formaldehyde (MF) loaded polyvinyl acetatepolyester nonwoven fabric composites," Journal of Thermoplastic Composite Materials, vol. 20, no. 3, pp. 305-322, 2007.

[3] J. I. Choi, J. H. Kim, K. W. Lee et al., "Comparison of gamma ray and electron beam irradiations on the degradation of carboxymethylcellulose," Korean Journal of Chemical Engineering, vol. 26, no. 6, pp. 1825-1828, 2009.

[4] M. Kato, H. Okamoto, N. Hasegawa, A. Tsukigase, and A. Usuki, "Preparation and properties of polyethylene-clay hybrids," Polymer Engineering and Science, vol. 43, no. 6, pp. 1312-1316, 2003.

[5] J. Sharif, K. Z. Mohd Dahlan, and W. M. Z. Wan Yunus, "Radiation crosslinked natural rubber/ethylene vinyl acetate/clay nanocomposites-effect of organoclay concentration," Journal of Nuclear and Related Technologies, vol. 5, no. 1, pp. 65-80, 2008.

[6] M. Zenkiewicz and J. Dzwonkowski, "Effects of electron radiation and compatibilizers on impact strength of composites of recycled polymers," Polymer Testing, vol. 26, no. 7, pp. 903907, 2007.

[7] A. Bhattacharya, "Radiation and industrial polymers," Progress in Polymer Science, vol. 25, no. 3, pp. 371-401, 2000.

[8] I. Banik and A. K. Bhowmick, "Influence of electron beam irradiation on the mechanical properties and crosslinking of fluorocarbon elastomer," Radiation Physics and Chemistry, vol. 54, no. 2, pp. 135-142, 1999.

[9] I. Banik, A. K. Bhowmick, V. K. Tikku, I. A. B. Majali, and R. S. Despande, "Effects of electron beam on the structural modification of the copolymeric and the terpolymeric fluorocarbon rubbers," Radiation Physics and Chemistry, vol. 51, pp. 195204, 1998.

[10] Q. T. Nguyen and D. G. Baird, "Preparation of polymer-clay nanocomposites and their properties," Advances in Polymer Technology, vol. 25, no. 4, pp. 270-285, 2006.

[11] S. Pavlidou and C. D. Papaspyrides, "A review on polymerlayered silicate nanocomposites," Progress in Polymer Science, vol. 33, no. 12, pp. 1119-1198, 2008.

[12] K. Premphet and W. Paecharoenchai, "Quantitative characterization of dispersed particle size, size distribution, and matrix ligament thickness in polypropylene blended with metallocene ethylene-octene copolymers," Journal of Applied Polymer Science, vol. 82, no. 9, pp. 2140-2149, 2001.

[13] M. Pramanik and S. K. Srivastava, "EVA/Clay nanocomposite by solution blending: effect of aluminosilicate layers on mechanical and thermal properties," Macromolecular Research, vol. 11, no. 4, pp. 260-266, 2003.

[14] I. Aravinda, P. Alberta, C. Ranganathaiahc, J. V. Kurianb, and S. Thomas, "Compatibilizing effect of EPM-gMA in EPDM/poly(trimethylene-terephthalate) incompatible blends," Polymer, vol. 45, pp. 4925-4937, 2004.

[15] S. Park, J. Krotine, S. A. B. Allen, and P. A. Kohl, "Electronbeam hardening of thin films of functionalized polynorbornene copolymer," Journal of Electronic Materials, vol. 35, no. 5, pp. 1112-1121, 2006.

[16] M. Hetzer, J. Naiki, H. Zhou, T. Poloso, and D. De Kee, “Thermal dependence of young's modulus of wood/polymer/clay nanocomposites," Journal of Composite Materials, vol. 43, no. 20, pp. 2285-2301, 2009.

[17] M. Mateev and S. Karageorgiev, "The effect of electron beam irradiation and content of EVA upon the gel-forming processes in LDPE-EVA films," Radiation Physics and Chemistry, vol. 51, no. 2, pp. 205-206, 1997.

[18] S. Kim and Y. C. Nho, "Effect of radiation on ultra high molecular weight polyethylene (UHMWPE)," International Energy Atomic Agency, vol. 1617, pp. 92-94, 2009.

[19] S. T. Olalekan, S. A. Muyibi, Q. H. Shah, M. F. Alkhatib, and F. Yusof, "Improving the polypropylene-clay composite using carbon nanotubes as secondary filler," Energy Research Journal, vol. 1, pp. 68-72, 2010.

[20] M. Bousmina, S. S. Ray, and J. Bandyopadhyay, "Thermal and thermo-mechanical properties of poly(ethylene terephthalate) nanocomposites," Journal of Industrial and Engineering Chemistry, vol. 13, no. 4, pp. 614-623, 2007.

[21] M. N. Bureau, F. Perrin-Sarazin, and M. T. Ton-That, "Polyolefin nanomposites: essential work of fracture analysis," Polymer Engineering and Science, vol. 44, pp. 1142-1151, 2004.

[22] H. J. Bray, S. A. T. Redfern, and S. M. Clark, "The kinetics of dehydration in Ca-montmorillonite: an in situ X-ray diffraction study," Mineralogical Magazine, vol. 62, pp. 647656, 1998. 

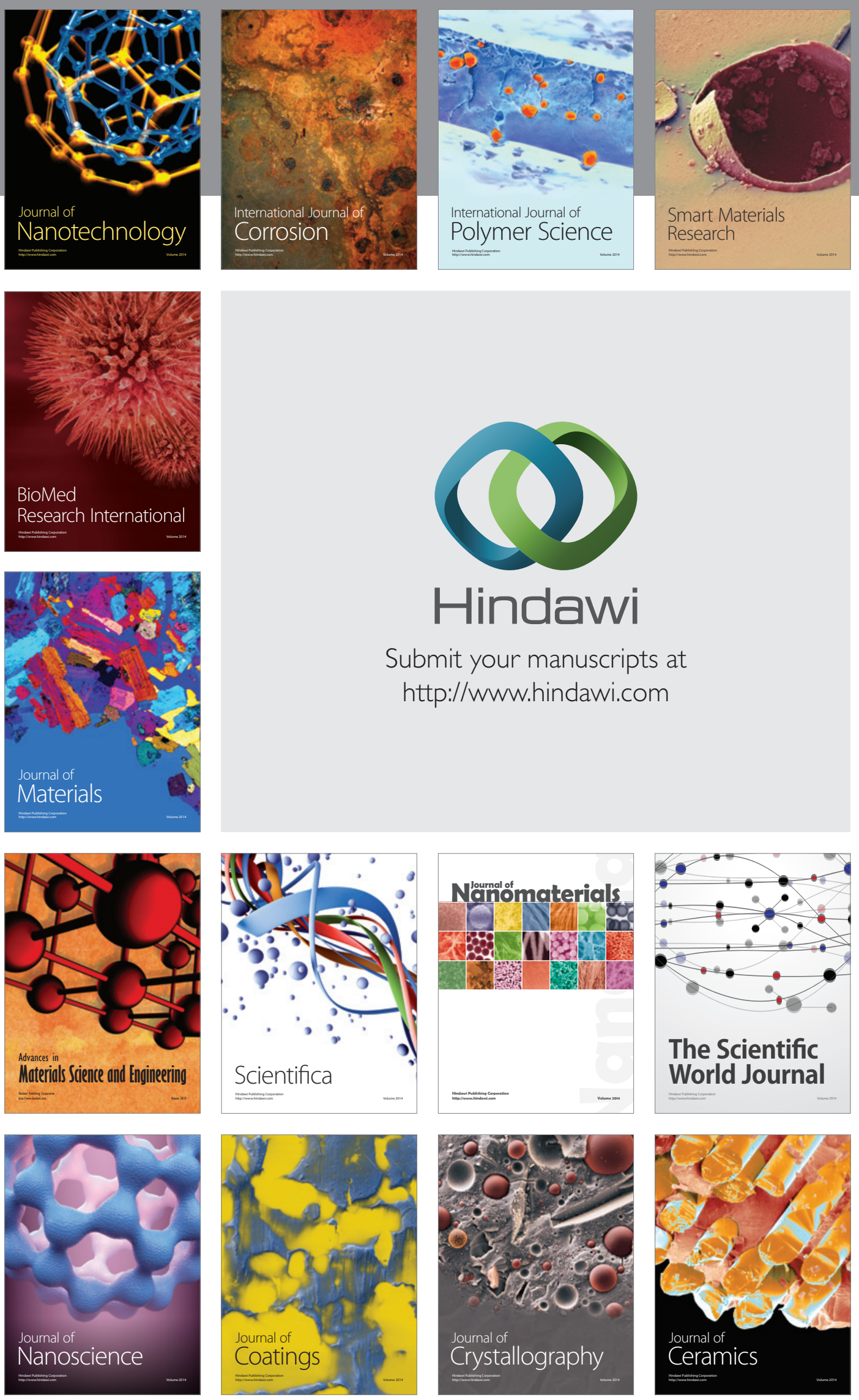

The Scientific World Journal

Submit your manuscripts at

http://www.hindawi.com

\section{World Journal}

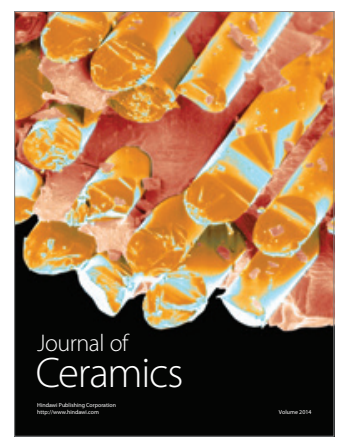

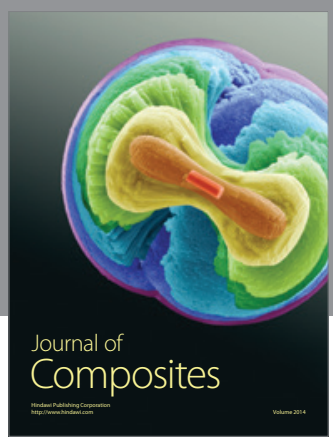
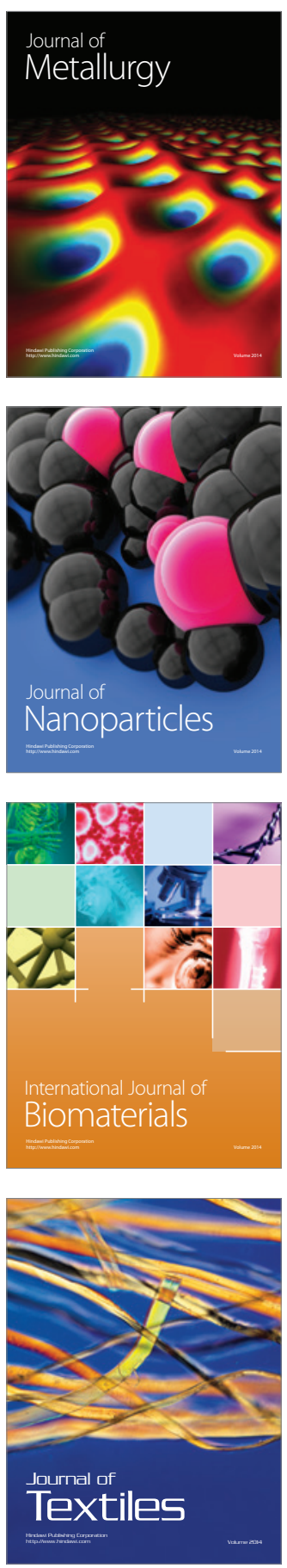